\title{
"Design for All" in Architectural Heritage conservation: the technology challenge
}

\author{
Vicente López-Mateu' ${ }^{1}$, Teresa M. Pellicer ${ }^{2}$ \\ ${ }^{1}$ Department of Architectural Construction, Universitat Politècnica de València, Spain, \\ ${ }^{2}$ Department of Construction Engineering, Universitat Politècnica de València, Spain.
}

\begin{abstract}
Among the United Nations 2030 objectives for the sustainable development, stand out those who seek social, economic and cultural equality of people, within the framework of different human settlements, their cultural heritage and the natural environment. This idea raises the need to establish effective strategies, resources and tools aimed to balance the current conditions in most disadvantaged groups, such as people with disabilities.

The situation is complicated because the barriers to integration and inclusivity are diverse, the initiatives, legislation and ways of acting are also very different. Therefore, overcoming the situation requires a broad multidisciplinary approach. On the other hand, Heritage resources can be a valuable mean for permanent and sustainable development, if there is a proper combination of different aspects: design, management and maintenance, continuous improvement and dissemination with inclusive criteria.

One of the possibilities to afford that difficult task is to promote in the field of university education different activities such as information exchange, crosscutting networks, research studies, experimental ICT tools development and adequate dissemination. This proposal is structured in this sense to arouse the interest and participation of teachers, students and researchers in these actions, establishing collaborative projects and work proposals.
\end{abstract}

Keywords: Design for all, Cultural Heritage conservation, Universal Accessibility, ICT for Inclusivity. 


\section{Introduction}

Among the 2030 sustainable development goals set by the United Nations, the following are included among the target indicators of Goal 10 "Reduce inequality within and among countries" (United Nations, 2015):

10.2 By 2030, empower and promote the social, economic and political inclusion of all, irrespective of age, sex, disability, race, ethnicity, origin, religion or economic or other status

10.3 Ensure equal opportunity and reduce inequalities of outcome, including by eliminating discriminatory laws, policies and practices and promoting appropriate legislation, policies and action in this regard

One of the reasons for inequality today is the limitations of physical, sensory or psychic type of some people who condition or prevent their access to certain natural or built spaces, tourist places, public resources, etc., and ultimately, live in the same conditions as the rest of the people.

Among these inequalities, we can highlight the problems of access to public, cultural and linked spaces to natural or built heritage. There are several, although scattered, initiatives and resources available following the principles of Universal Design or design for all (M. Story, Mueller, \& Mace, 1998). From 1998, these studies are trying to relieve or improve the situation (Patrick Langdon, Lazar, Heylighen, \& Dong, 2018; M. F. Story, 1998).

On the other hand, there is a tendency nowadays to properly use the resources of cities to achieve universal cultural diffusion, leisure activities and sustainable tourism. The opportunities are based on the preservation of heritage environments, natural or built, balanced development mechanism in certain areas or territories facilitating universal accessibility. In this sense, digital resources and software applications can be used in Cultural Heritage to overcome the barriers and develop the sustainable tourism (Addison, 2001; Bruno et al., 2018; Ruffino et al., 2019)

In this sense, Goal 11 "Make cities and human settlements inclusive, safe, resilient and sustainable" proposes the following goals related to accessibility to heritage resources (United Nations, 2015):

11.3 By 2030, enhance inclusive and sustainable urbanization and capacity for participatory, integrated and sustainable human settlement planning and management in all countries

11.4 Strengthen efforts to protect and safeguard the world's cultural and natural heritage 
11.7 By 2030, provide universal access to safe, inclusive and accessible, green and public spaces, in particular for women and children, older persons and persons with disabilities

11.A Support positive economic, social and environmental links between urban, peri-urban and rural areas by strengthening national and regional development planning

\section{Background}

The UPV work team has teachers who have taught courses and seminars on this topic. Projects, study cases and examples of accessibility in Heritage in Valencia and its province have been analysed with students, both in public space and in different Heritage buildings.

The experience has been very satisfactory, also involving professionals from other universities and the Public Administration. To advance the proposal, collaborations of partners who have worked in this field, especially in software applications, are needed to adapt them to this topic.

\section{Proposal approach}

The proposed initiative tries to collect in a transversal way those aspects of design, evaluation of the current state, improvement of the management and diffusion, as well as of the development of the territory incorporating them to the university academic formation.

This proposal is intended to involve students and teachers of different university degrees to develop studies, lines of research and computer APP, which facilitate the inclusiveness of people with some type of disability.

Therefore, this proposal aims to find partners from European universities that want to participate in this joint project of approximation to the different resources of cultural heritage to all people.

\subsection{Objectives}

The main objective of the proposal will be to create a network of partners between European Universities for the promotion of universal access to natural and built heritage, to create safe, inclusive and accessible environments, through the use of communication and information systems (ICT).

This main objective is developed through the following secondary objectives:

1. Create an information exchange platform with examples of good practices.

2. Submit proposals to public research calls. 
3. Exchange experiences in training through seminars, courses or conferences.

4. Encourage internship and final master's work on issues of universal accessibility and inclusiveness in natural and built heritage.

5. Develop computer tools that facilitate inclusiveness and universal accessibility.

\subsection{Work plan}

To achieve the stated objectives, the following work plan is proposed:

First: To analyse the current situation in the different countries of the European Union

Second: To study the state-of-the-art in different areas from a multidisciplinary perspective: natural spaces, urban planning, architecture, archaeology, museums, etc.

Third: To analyse and compare the guides and recommendations, as well as the regulations of the different countries of the European Union.

Fourth: To create an information exchange platform to share publications, scientific articles, news, events, etc., and disseminate them.

Fifth: To develop software applications (app) to facilitate inclusiveness and accessibility to natural and built heritage.

Sixth: To supervise projects and master thesis that propose analysis and solutions in locations that present problems, needs or risks.

Seventh: To publish the results.

\section{References}

Addison, A. A. (2001). Virtual Heritage - Technology in the Service of Culture. In VAST 2001: Virtual Reality, Archaeology, and Cultural', (pp. 1-12). https://doi.org/10.1145/584993.585055

Bruno, F., Barbieri, L., Lagudi, A., Cozza, M., Cozza, A., Peluso, R., \& Muzzupappa, M. (2018). Virtual dives into the underwater archaeological treasures of South Italy. Virtual Reality, 22(2), 91-102. https://doi.org/10.1007/s10055-017-0318-z

Langdon, Patrick, Lazar, J., Heylighen, A., \& Dong, H. (2018). Breaking down barriers : usability, accessibility and inclusive design. (Pat Langdon, J. Lazar, A. Heylighen, \& H. Dong, Eds.). Springer. https://doi.org/https://doi.org/10.1007/978-3-319-75028-6

United Nations, U. (2015). Sustainable Development Knowledge Platform. Retrieved October 9, 2019, from https://sustainabledevelopment.un.org/\#

Ruffino, P. A., Permadi, D., Gandino, E., Haron, A., Osello, A., \& Wong, C. O. (2019). DIGITAL TECHNOLOGIES FOR INCLUSIVE CULTURAL HERITAGE: THE CASE STUDY OF SERRALUNGA D'ALBA CASTLE. In ISPRS Annals of Photogrammetry, Remote Sensing and Spatial Information Sciences (Vol. IV-2/W6, 
pp. 141-147). https://doi.org/10.5194/isprs-annals-iv-2-w6-141-2019

Story, M. F. (1998). Maximizing Usability: The Principles of Universal Design. Assistive Technology, 1O(1), 4-12. https://doi.org/10.1080/10400435.1998.10131955

Story, M., Mueller, J. L., \& Mace, R. L. (1998). The Universal Design File: Designing for People of All Ages and Abilities. Design Research and Methods Journal, 1(5), 165. https://doi.org/10.1073/pnas.95.12.6854 